\title{
КРОСС-КУЛЬТУРНЫЕ ИССЛЕДОВАНИЯ
}

УДК $39+316.723$

DOI: $10.33876 / 2311-0546 / 2020-51-3 / 120-135$

(С) Д.А. Дронова, М.Л. Бутовская

\section{ПРЕДПОЧТЕНИЯ В ВЫБОРЕ БРАЧНОГО \\ ПАРТНЕРА У МУЖЧИН И ЖЕНЩИН \\ В ИНДИЙСКОЙ ДИАСПОРЕ ТАНЗАНИИ*}

В статье представлень результаты исследования, проведенного среди представителей индийской диаспоры в Танзании. Полученные данные подтверждают универсальные гендерные различия в выборе брачного партнера и согласуются с предсказаниями теории сексуальных стратегий. Индийцы-мужчины склонны уделять больше внимания репродуктивным способностям женщины, оценивая физические показатели представительнич, женского пола, свидетельствуюшие о фертильности, здоровье и возрасте, а также черты заботливой матери. Женщины считают цуенными те мужские качества, которые говорят о его способностях обеспечивать семью, а значит и совместных детей, это уровень интеллекта, хорочее образование, сочиильный статус, трудолюбие, финансовая обеспеченность и т.n. В тоже время культурные компоненты, характерные для индийского общества, оказывают влияние на выбор брачного партнера. Кастовая принадлежность, роль родительского мнения относительно будущего супруга или супруги остаются важными критериями. Вместо одностороннего движения в сторону западных брачных практик, как это предполагается теориями изменения семьи и встречается в других азиатских контекстах (например, Китай), тенденции в индийском обществе указывают на промежуточный вариант совмещения традиционных индийских и западных норм.

Ключевые слова: выбор брачного партнера, индийская диаспора, брак по сговору, Индия, Танзания

Дронова Дарья Алексеевна - младший научный сотрудник, Институт этнологии и антропологии РАН (119991 Москва, Ленинский проспект 32а). Эл. почта: dariadronova@yandex.ru. Dronova, Daria A. - Institute of Ethnology and Anthropology RAS (Moscow, Russia). E-mail: dariadronova@, yandex.ru

Бутовская Марина Львовна - член-корр. РАН, д.и.н., профессор, главный научный сотрудник, зав. центром, Институт этнологии и антропологии РАН (119991 Москва, Ленинский проспект, 32a). Эл. почта: marina.butovskaya@gmail.com. Butovskaya, Marina L. - Corresponding member of RAS, Dr. in Hist., Head of the Centre, Institute ethnology and anthropology RAS (Moscow, Russia). E-mail: marina.butovskaya@gmail.com

* Дронова Д.А. исследование выполнила при поддержке РФФИ в рамках проекта № 18-39-00128. Бутовская М.Л. исследование выполнила в соответствии с планом научно-исследовательских работ Института этнологии и антропологии РАН. 
Согласно теории, предложенной эволюционным биологом Робертом Трайверсом, родительский вклад представляет собой любой вклад родителя в своего потомка, увеличивающий шансы на выживание последнего (и следовательно, его репродуктивный успех) ценою снижения возможностей родителей вкладывать в других потомков (Trivers 1972). Отталкиваясь от исходной предпосылки о том, что мужчина и женщина затрачивают разное количество усилий на воспроизводство и воспитание потомства, Р. Трайверс доказал, что родительский вклад неравнозначен у представителей противоположных полов. В связи с этим ученый сделал следующие заключения (Trivers 1972): а) самка более избирательна при выборе партнера, так как за свою жизнь она имеет возможность произвести меньшее количество отпрысков по сравнению с самцом. Главные качества самца, на которые самка будет ориентироваться - желание обеспечивать ресурсами партнершу и проявлять заботу о совместном будущем потомстве; б) способность оставить после себя большее число потомков при минимальных затратах. Эти идеи получили дальнейшее развитие в труде Д. Саймонса «Эволюция человеческой сексуальности» (Symons 1979). Основываясь на данных по разным культурам, Д. Саймонс продемонстрировал применимость теории родительского вклада Р. Трайверса к человеческим обществам. По всему миру женщины более избирательны и требовательны в выборе полового партнера, а мужчины менее разборчивы и более полигамны. Он также указал на психологические различия мужчин и женщин в плане сексуальности: мужчины в большей степени склонны к сексуальному разнообразию. В соответствии с этими особенностями Д. Саймонс выдвинул гипотезу о различии гендерных предпочтений при выборе партнера. Мужчины должны преимущественно ориентироваться на показатели фертильности и репродуктивности партнерши, а женщины - больше ценить в партнере желание и возможность заботиться и обеспечивать совместных детей. Поэтому ценными мужскими качествами по мнению женщин являются те, которые говорят о его способностях обеспечивать семью и совместных детей, а именно в условиях индустриальных обществ это уровень интеллекта, хорошее образование, социальный статус, трудолюбие, финансовая обеспеченность и т.п. Что касается традиционных обществ, для женщин будут важными качества, которые помогут мужчине обеспечить семью продуктами питания посредством охоты, рыболовства, фермерства и лидерские черты. Для того чтобы оценить репродуктивные способности женщины, мужчины полагаются на физические показатели представительниц женского пола, свидетельствующие о фертильности, здоровье и возрасте. Под физическими показателями, которые формируют привлекательность женщины в глазах мужчины, подразумевается рост, вес, форма и флуктуирующая асимметрия лица, соотношение талии к бедрам, длина ног и др.

В 1990 г. была опубликована одна из основополагающих работ по теме выбора брачного партнера эволюционным психологом Д. Бассом с соавторами (Buss et al. 1990). Д. Басс организовал в 37 странах исследование по единой программе. Ученым были выделены универсальные показатели, влияющие на выбор брачного партнера во всех популяциях и имеющих гендерные различия. Тем не менее, автор с коллегами отмечают, что культура играет важную роль в традиционных обществах (в выборке данного исследования это - Китай, Индия, Иран, Нигерия). В дальнейшем его идеи получили широкое распространение и неоднократно проверялись у разных этнических групп. Стоит отметить, что в основном это были индустриальные общества, для которых подтверждались выдвинутые положения. Однако начавшийся в начале XXI в. всплеск исследований традиционных обществ показал неоднозначность и невозможность экстраполяции накопленных знаний на человеческие культуры по всему миру. 
В другой, также знаковой, работе Д. Басс поднял вопрос о релевантности данных о гендерных различиях выбора брачного партнера в случае браков по сговору родителей (Buss 1989). Индия как раз является страной, где традиционно браки организовывались исключительно родителями. Несмотря на то, что родители выбирают брачного партнера для своих детей, наличие предпочтений, ассоциированных с репродуктивными стратегиями, имеет место. В обществах с организованными браками сыновья и дочери могут оказывать влияние на выбор будущего супруга, выражая свое мнение или с помощью различных хитростей (O'Kelly, Carney 1986).

$\mathrm{C}$ конца $\mathrm{XX}$ в. ученые обратились к проблеме удовлетворенности браком в зависимости от типа системы выбора брачного партнера - самостоятельного выбора супругов или организованного родителями брака. Подобные исследования проводились во многих странах, в которых практиковались и практикуются браки по сговору родителей. Тем не менее, общего знаменателя не было найдено. Так было показано, что период ухаживания, совместное проживание до брака и тип способа выбора брачной пары минимально коррелирует с удовлетворенностью браком среди молодых супружеских пар в Израиле (Shachar 1991). Авторы другого исследования (Myers et al. 2005) сравнили уровень удовлетворенности браком и качеством взаимоотношений между тремя группами супружеских пар: 1. индийцев, имевших брак по сговору; 2. индийцев, сделавших самостоятельный выбор супруга; 3. американских супружеских пар. Оказалось, что максимальные оценки удовлетворенностью браком и более теплые отношения характерны для индийских пар, которым родители подобрали супруга/у (Yelsma, Athappilly 1988). $\mathrm{B}$ тоже время на китайской выборке получены противоположные результаты (Xu, Whyte 1990). Китаянки указывали на большую удовлетворенность брачным союзом в случае самостоятельного выбора супруга. Таким образом, общий массив публикаций по удовлетворенности браком с учетом типа выбора брачного партнера (самостоятельный или организованный родителями) делится на три группы в зависимости от полученных результатов: 1. Качество брака оценивается выше при самостоятельном выборе супруга/и, чем при браке по сговору (Allendorf, Ghimire 2013; Demir, Fisiloglu 1999; Hortaçsu 1999, 2007; Lev-Wiesel, Al-Krenawi 1999; Pimentel 2000; Xu, Whyte 1990); 2. Качество брака оценивается выше в организованном браке, чем при самостоятельном выборе (Gupta, Singh 1982; Yelsma, Athappily 1988); 3. Не наблюдается достоверной разницы в оценках удовлетворенностью браком в зависимости от типа выбора брачного партнера (Hoelter et al. 2004; Myers et al. 2005; Regan et al. 2012; Shachar 1991; Schwartz 2007). Из вышеперечисленного следует вывод, что культурные детерминанты в сочетании с универсальными стратегиями оказывают существенное влияние на выбор брачного партнера во всех обществах. Одни и те же качества потенциального брачного партнера в разных культурных средах могут иметь различную или даже противоположную эволюционную адаптацию и, соответственно, социокультурную интерпретацию.

Однако в одном из недавних исследований удовлетворенности браком в зависимости от типа выбора брачного партнера (самостоятельно или по сговору родителей), проведенном в Бангладеш, акцент сделан на возможности оказывать влияние на выбор будущего супруга женщиной (Flicker et al. 2019). Стоит оговориться, что в данном случае участниками опроса были только женщины. Результаты показали, что женщины, по крайней мере на начальных этапах брака, оказывающие влияние на выбор брачного партнера независимо от типа брака (организованного или самостоятельного решения), оценивают брачные отношения как более счастливые. По мнению авторов исследо- 
вания, существует, по меньшей мере, два процесса, вследствие которых возможность влиять на выбор брачного партнера соотносится с более высоким качеством брака, близостью, страстью и привязанностью друг к другу. Во-первых, возможность наложить вето на нежелательных кандидатов значительно снижает вероятность оказаться в паре с непонравившимся партнером (Xu, Whyte 1990). Во-вторых, сама идея о том, что партнер имел возможность наложить вето, но не сделал этого, может способствовать созданию условий, повышающих вероятность развития любви и повышения качества брака. Если женщина имеет большее влияние на выбор партнера (а) ее партнер может чувствовать себя уверенным, что она приняла его, несмотря на ее способность наложить вето, и (б) она также может считать, что ее партнер одобрил ее, несмотря на его способность отвергнуть ее. В супружеских парах, у которых отсутствовала возможность повлиять на выбор партнера, взаимная симпатия и связь с партнером может устанавливаться в течение более продолжительного времени.

Цель данного исследования - проанализировать гендерные различия в стратегиях выбора брачного партнера в индийской диаспоре, проживающей в Танзании, и подтвердить гипотезы об их универсальности у современного человека. Были поставлены следующие задачи: 1. Выявить наиболее важные качества, лежащие в основе выбора постоянного полового партнера по мнению мужчин и женщин. 2. Определить культурную специфику выбора брачного партнера у представителей индийской диаспоры в Танзании. 3. Сопоставить эти критерии выбора брачного партнера у индийцев, проживающих в Танзании и у индийцев, проживающих на территории Индии.

\section{Выборка}

Исследование проводилось в г. Дар-эс-Салам (Танзания) среди представителей индийской диаспоры. Общее число респондентов составило 315 человек. Из них 164 мужчины и 151 женщина. Возрастной разброс составил от 17 до 78 лет. Средний возраст - 38,8 $\pm 12,3$ лет. Приверженцев индуизма 202 человека, ислама 104 человека, 9 респондентов не указали религиозную принадлежность. Несмотря на то, что все респонденты сейчас живут в г. Дар-эс-Салам, родились в Танзании 182 человека, в Индии - 117 респондентов и 7 человек в других странах (Малайзия, Объединенные арабские Эмираты, Великобритания, Йемен, Пакистан).

\section{Методы}

Данные были собраны методом анкетирования и интервьюирования. В первой части анкеты респондентам предлагалось указать свои социо-демографические данные, во второй необходимо было оценить 27 качеств потенциального брачного партнера по шкале от 1 до 3, где 1- самая высокая оценка, 3 - самая низкая.

Общий массив данных обрабатывался с помощью статистического пакета SPSS-22. Метод распределения частот позволил дать количественную характеристику собранных данных. Метод корреляционного анализа использовался для определения взаимосвязи ряда характеристик. Для установления главных факторов, определяющих выбор брачного партнера как у мужчин, так и у женщин, был использован метод главных компонент. Каждый из полученных факторов объединяет переменные с высокой степенью взаимосвязи между собой. С помощью теста Хи-квадрат $\left(\chi^{2}\right)$ проверялась зависимость между полученными главными компонентами, описывающими критерии выбора брачного партнера, и религиозной принадлежностью респондентов с разбивкой по полу. 


\section{Результаты}

Рассмотрим главные компоненты, определяющие выбор брачного партнера мужчинами и женщинами в индийской диаспоре Танзании. На основе оценок 27 качеств потенциального брачного партнера были получены представления о критериях выбора супруга/и. Результаты факторного анализа определили четыре главные компоненты, определяющие выбор брачного партнера, для каждого пола (табл. 1 и 2). Так, предпочтения индийцев-мужчин выражены следующими главными компонентами, описывающими 51,4\% общей изменчивости. Главная компонента 1 (16,8\% общей изменчивости) ассоциируется с качествами потенциальной жены с достаточно высоким статусом, образованной и хорошими репродуктивными возможностями. Главная компонента 2, описывающая 13,5\% общей изменчивости, демонстрирует фактор физической привлекательности и заботливой матери. Главная компонента 3 (11,8\% общей изменчивости) является фактором социабельности. Главная компонента 4 (9,3\% общей изменчивости) отражает негативные качества потенциальной брачной партнерши.

Главные компоненты, выражающие мнение женщин относительно брачного партнера, в целом схожи с критериями мужчин. Четыре главные компоненты объясняют 47,5\% суммарной дисперсии. Главная компонента 1 (16,7\% общей изменчивости) характеризует «хорошего» мужа, способного обеспечить жену и детей. Главная компонента 2 (10,6\% общей изменчивости) обобщает показатели, характеризующие внешность будущего супруга. Главная компонента 3 (10,5\% общей изменчивости) отражает способность потенциальным брачным партнером налаживать социальные связи. Главная компонента 4 (9,7\% общей изменчивости) представляет собой фактор нежелательных качеств будущего супруга.

Для каждой из четырех главных компонент был проведен тест Хи-квадрат с учетом гендерной принадлежности. Так, по всем четырем главным компонентам, отражающим предпочтения мужчин-индийцев относительно будущей супруги, не было получено достоверных различий по религиозному признаку респондентов (ГК 1: $\chi^{2}=1,19 ; \mathrm{df}=3 ; \mathrm{p}=0,755 ;$ ГК $2: \chi^{2}=0,59 ; \mathrm{df}=3 ; \mathrm{p}=0,899 ;$ ГК $3: \chi^{2}=3,42 ; \mathrm{df}=3 ; \mathrm{p}=0,332 ;$ ГК 4: $\left.\chi^{2}=1,19 ; \mathrm{df}=3 ; \mathrm{p}=0,755\right)$. Главные компоненты 2,3 и 4, сформированные из более высоких оценок женщин качеств потенциального супруга, также не имеют достоверной зависимости от религиозной приверженности респонденток (ГК $2: \chi^{2}=6,05$; $\mathrm{df}=3 ; \mathrm{p}=0,109 ;$ ГК $3: \chi^{2}=3,09 ; \mathrm{df}=3 ; \mathrm{p}=0,377 ;$ ГК 4: $\left.\chi^{2}=5,31 ; \mathrm{df}=3 ; \mathrm{p}=0,150\right)$. В данном случае интерес вызывает главная компонента 1 , для которой выявлена достоверно значимая связь в оценке качеств этой компоненты в зависимости от приверженности респонденток к индуизму и исламу $\left(\chi^{2}=8,27 ; \mathrm{df}=3 ; \mathrm{p}=0,041\right)$. Женщины, исповедующие индуизм, и женщины, исповедующие ислам, в разной степени оценивают качества потенциального брачного партнера, определяющие главную компоненту 1. Индуистки придают большее значение показателям взаимности чувств $(\mathrm{t}=3,020$; $\mathrm{df}=81,50 ; \mathrm{p}=0,003)$, финансовой обеспеченности $(\mathrm{t}=4,148 ; \mathrm{df}=80,45 ; \mathrm{p}=0,000)$, трудолюбию $(\mathrm{t}=2,118 ; \mathrm{df}=66,74 ; \mathrm{p}=0,038)$ и социальному статусу $(\mathrm{t}=2,789 ; \mathrm{df}=74,85$; $\mathrm{p}=0,007)$ будущего брачного партнера по сравнению с мусульманками. 
Таблица 1

Главные компоненты, описывающие основные качества потенциальной супруги по мнению мужчин

\begin{tabular}{|c|c|c|c|c|}
\hline \multirow{2}{*}{ Характеристики } & \multicolumn{4}{|c|}{ Главные компоненты } \\
\hline & ГК1 & ГК2 & ГКЗ & ГК 4 \\
\hline Любовь к детям &, 227 & ,365 &, 152 &,- 400 \\
\hline Трудолюбие & 645 &, 053 &, 182 &, 024 \\
\hline Социальный статус & 651 &,- 091 &, 183 &,- 099 \\
\hline Взаимность чувств & ,633 &,- 010 &, 157 &,- 277 \\
\hline Финансовая обеспеченность &, 259 &,- 088 & ,455 & ,269 \\
\hline Схожесть жизненных интересов & ,722 &, 003 &, 133 &, 030 \\
\hline Здоровье & ,397 &, 369 &, 123 &,- 251 \\
\hline Способность к деторождению & ,632 & ,203 &,- 084 &,- 200 \\
\hline Возраст & ,668 &, 377 &, 046 &,- 104 \\
\hline Интеллект &, 522 & ,268 &, 315 &,- 190 \\
\hline Уровень образования &, 543 &, 315 & ,314 &, 158 \\
\hline Хозяйственность &, 265 &, 525 &, 244 &,- 122 \\
\hline Активность &, 438 &, 403 & ,293 & ,211 \\
\hline Способность постоять за себя & ,468 & ,381 & ,435 & ,079 \\
\hline Лидерство & ,350 &, 024 & ,588 & ,094 \\
\hline Заботливость & ,273 &, 529 & ,423 &,- 225 \\
\hline Способность быть одному & ,098 &,- 053 & 633 &,- 050 \\
\hline Общительность &, 097 &, 356 &, 721 &,- 024 \\
\hline Чувство юмора &, 354 &, 301 & ,411 &, 112 \\
\hline Этническая принадлежность &,- 021 & 143 & ,694 &,- 286 \\
\hline Склонность к риску &, 300 &, 341 &, 345 &, 246 \\
\hline Девственность &,- 030 &,- 005 &, 114 &, 847 \\
\hline Наличие детей от другого &,- 082 &, 082 &, 008 &, 822 \\
\hline Вредные привычки &,- 357 & ,248 &,- 230 &, 513 \\
\hline Внешность &,- 082 &, 720 &, 068 &,- 068 \\
\hline $\mathrm{Bec}$ &,- 042 & ,816 &,- 106 & ,157 \\
\hline Рост & 199 & ,722 & 057 & ,195 \\
\hline
\end{tabular}

* Метод вращения: варимакс с нормализацией Кайзера 
Таблица 2

Главные компоненты, описывающие основные качества потенциального супруга по мнению женщин

\begin{tabular}{|c|c|c|c|c|}
\hline \multirow{2}{*}{ Характеристики } & \multicolumn{4}{|c|}{ Главные компоненты } \\
\hline & ГК1 & ГК2 & Гкз & ГК4 \\
\hline Любовь к детям & ,093 &,- 161 &, 131 &, 138 \\
\hline Трудолюбие & ,239 &,- 121 & ,494 &,- 320 \\
\hline Социальный статус & ,348 &, 353 & ,334 &,- 335 \\
\hline Взаимность чувств & ,641 &, 012 &, 141 &,- 019 \\
\hline Финансовая обеспеченность & ,611 &,- 003 &, 018 &,- 143 \\
\hline Схожесть жизненных интересов & ,673 &, 034 & ,225 &, 014 \\
\hline Здоровье & ,531 & ,349 &,- 168 & ,079 \\
\hline Способность к деторождению & ,588 &, 211 &, 112 &, 100 \\
\hline Возраст & ,579 & ,272 &,- 014 &, 126 \\
\hline Интеллект & ,692 &, 114 & ,205 &, 061 \\
\hline Уровень образования & ,614 & ,272 &, 013 &, 062 \\
\hline Хозяйственность & ,267 & ,207 & ,214 & ,477 \\
\hline Активность &, 125 &, 305 & 629 & ,139 \\
\hline Способность постоять за себя & ,165 &, 228 & ,648 & ,365 \\
\hline Лидерство & ,225 &, 016 & ,630 &, 030 \\
\hline Заботливость & ,439 &, 073 & ,277 &, 129 \\
\hline Способность быть одному &,- 133 &,- 118 &, 553 &, 038 \\
\hline Общительность & ,543 &, 051 & ,311 &, 183 \\
\hline Чувство юмора &, 531 &, 099 & ,415 &, 020 \\
\hline Этническая принадлежность & ,265 &, 284 & ,266 &,- 111 \\
\hline Склонность к риску &, 253 &, 144 & ,480 &, 112 \\
\hline Девственность &,- 100 &,- 066 &, 224 &, 788 \\
\hline Наличие детей от другого & 083 &,- 100 &, 035 & ,806 \\
\hline Вредные привычки & ,095 &,- 029 &,- 061 &, 763 \\
\hline Внешность & ,314 & ,719 & ,212 &,- 057 \\
\hline $\mathrm{Bec}$ & ,183 & ,862 & ,058 & ,078 \\
\hline Рост &, 163 &, 876 &, 044 &,- 061 \\
\hline
\end{tabular}

* Метод вращения: варимакс с нормализацией Кайзера 


\section{Обсуждение}

Более детальный анализ полученных главных компонент, определяющих выбор брачного партнера представителями индийской диаспоры как мужчинами, так и женщинами, демонстрирует согласованность с предсказаниями теории сексуальных стратегий. Так главная компонента 1, основанная на мнении мужчин, включает в себя следующие показатели: трудолюбие, социальный статус, взаимность чувств, схожесть жизненных интересов, интеллект, образование, фертильность, возраст. Перечисленные качества свидетельствуют о предпочтении мужчинами партнерши со схожими жизненными установками, соответствующего социального статуса и интеллектуального развития, а также имеющей хорошие репродуктивные возможности. Социально-психологические характеристики будут оказывать влияние на способность сохранять крепкие семейные отношения, что в свою очередь обеспечит будущим совместным детям благоприятные условия для жизни и дальнейшие перспективы. Лонгитюдное исследование супружеских пар в сельских районах Непала подтверждает более высокий уровень образования детей и отсутствие желания покинуть родительский дом в более раннем возрасте, в тех семьях, где у родителей наблюдается более сильная положительная эмоциональная связь (Brauner-Otto et al. 2020). Также ряд других работ демонстрирует более высокую социальную успешность и репродуктивное поведение потомства в семьях с более устойчивыми позитивными взаимоотношениями между матерью и отцом (удовлетворенность браком, отсутствие разводов, раздоров и т.п.) (Cherlin et al. 1995; Malinen et al. 2010; Thornton et al. 2007).

Важными качествами потенциальной супруги, которые также входят в ГК 1 по мнению мужчин, являются возраст и способность к деторождению. Возраст определяет фертильные возможности партнерши. В связи с этим в эволюционной перспективе мужчины предпочитают партнершу младше себя, а женщины выбирают старших партнеров относительно своего возраста. Более того в некоторых странах на показателе возраста завязаны культурные нормы при выборе брачного партнеpa, связанные, например, с размером затрат на добрачные выплаты (Conroy-Beam, Buss 2018). Детальный анализ наших данных подтверждает, что мужчины и женщины достоверно различаются по предпочтению возраста будущего супруга. 59,8\% респондентов-мужчин желают, чтобы невеста была младше. В то время, как 73,5\% женщин хотят мужа старше себя. Только 2,4\% представителей мужского пола согласны иметь жену старше себя и $1,3 \%$ женщин - брачного партнера, который будет младше. Ровесники интересуют 22,0\% мужчин и $14,6 \%$ женщин. Возраст не имеет значения для 12,8\% мужчин и 9,3\% женщин. Также наш материал показал значимые гендерные различия относительно возраста вступления в брак. Средний возрастной

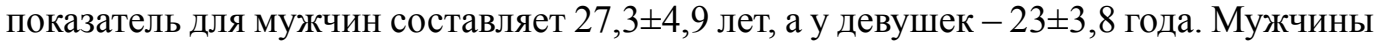
нашей выборки женились, начиная с 18 лет и до 51 года. Респондентки отметили возраст вступления в брак от 17 до 43 лет. Наиболее активный период вступления в брак приходится на промежуток с 23 до 30 лет у мужчин и с 19 до 27 лет у женщин. Согласно переписи населения в Индии 2011 г. пик заключения брачных союзов у мужчин с 25 до 39 лет, а у женщин - с 20 до 39 лет (C-2 Marital Status by Age and Sex). Тем не менее возраст 19 лет считается наиболее фертильным для женщин (Symons 1979; Williams 1975). Именно в этом возрасте в традиционных культурах женщины рожают первого ребенка (Северцева 1999; Седловская 1999). 
Повышающийся уровень образования в целом, но в большей степени женщин, вносит существенные изменения в брачные отношения. Повышается возраст вступления в брак, уменьшается количество детей в семье, повышаются требования к брачным партнерам. В среднем, индийская семья в Дар-эс-Саламе имеет двух детей. Из числа опрошенных семейных индийцев таковых оказалось - 48,3\%. Один ребенок у $22 \%$ респондентов, три - у $15,7 \%$, а у 4,2\% - четверо детей. Большинство индийцев предпочитают иметь двоих детей. Небольшое количество отпрысков индийцы объясняют финансовыми ресурсами. Они говорят, что лучше иметь меньше детей и дать им больше возможностей. Родители-индийцы уделяют много внимания образованию своих чад и готовы вкладывать в него значительные финансовые средства. Кроме школы дети посещают дополнительные занятия - спортивные секции, музыкальные уроки, языковые курсы. Данные ООН свидетельствуют о влиянии повышающегося уровня образования на рождаемость. Население ответственнее начинает относиться к рождению ребенка, думая о его будущем. Наше исследование по сходной тематике среди студентов-африканцев показывает, что они также нацелены на снижение рождаемости для обеспечения более качественной жизни своим детям (Бутовская и др. 2008).

ГК 2 по мнению мужчин тесно связана с фертильными возможностями партнерши и более четко раскрывает качества, свидетельствующие о репродуктивном успехе. Это фактор физической привлекательности и заботливой матери. Индийцы-мужчины склонны уделять больше внимания репродуктивным способностям женщины, оценивая физические показатели представительниц женского пола, свидетельствующие о фертильности, здоровье, а также качества заботливой матери. Данные по студентам индийского штата Карнатака подтверждают гендерную специфику при выборе брачного партнера (Murry, Pujar 2018). Мужчины чаще ценят красивую внешность партнерши, а женщин более заинтересованы ресурсным потенциалом будущего супруга. Характеристики, связанные с приобретением ресурсов, такие как уровень образования, финансовая обеспеченность, социальный статус, трудолюбие, предпочитались женщинам больше, чем мужчинам. С другой стороны, умение потенциальным партнером хорошо вести хозяйство важнее для мужчин, чем для женщин. Однако приятная внешность и хорошие финансовые перспективы, как правило, не входили в число самых желаемых характеристик для обоих полов. А добрые и понимающие, здоровые и умные возглавляли рейтинг независимо от пола. Исследования, проведенные среди российского, танзанийского и замбийского студенчества по сходному инструментарию с представленным в данном проекте, также свидетельствуют о наличии гендерных различий в выборе брачного партнера, но и выявляют культурно-специфические параметры, влияющие на брачное поведение в конкретном обществе (Бутовская, Смирнов 2003; Бутовская и дp. 2008). Физические показатели, как маркеры репродуктивного потенциала партнерши, являются значимыми в большей степени для мужчин, чем для женщин (Buss 1999; Kendrik et al. 1994; Mealey 2000).

Как уже подчеркивалось выше, женщины склоны оценивать мужчин с позиции материального достатка, перспектив и социальной успешности. Именно эти качества соответствуют по мнению женщин в ГК 1 и ГК 3 чертам «хорошего» мужа, способного обеспечить жену и детей, и дают возможность потенциальным брачным партнером налаживать социальные связи. Женщины склонны придавать 
большее значение наличию высокого уровня образования, интеллекта, материального положения потенциального постоянного партнера (Pawlowski, Koziel 2002; Waynforth, Dunbar 1995).

Ранее опубликованные наши данные по этой же выборке подтверждают высокую значимость культурного компонента в выборе брачного партнера не только среди индийцев, проживающих непосредственно в Индии, но и в индийской диаспоре в Танзании (Дронова 2014; Дронова 2018), а опираясь на опубликованные материалы других ученых, можно говорить - в индийских диаспорах по всему миру.

Нам удалось установить схожесть основных принципов брачевания: эндогамии и экзогамии, практикующихся как в индийской диаспоре в Танзании, так и на территории Индии. Абсолютное большинство мужчин $(56,1 \%)$ и женщин $(72,8 \%)$ выразили желание иметь будущего партнера из схожей касты. Каста продолжает оставаться основным критерием при выборе потенциального партнера для брака. Индийцы во всем мире, как в диаспоре, так и в Индии, обращают внимание в первую очередь на принадлежность к одной касте. Правда, исследования, посвященные индийской диаспоре на Карибских островах, свидетельствуют о снижении и ликвидации кастового сознания (Roopnarine 2006). Однако аналогичные исследования в США показывают, что кастовая иерархия по-прежнему преобладает среди индийской диаспоры (Adur, Narayan 2017; Maira 2012). Объясняется это тем обстоятельством, что важным отличием между индийскими диаспорами в Карибском бассейне и США является происхождение первых из низших каст наемных рабочих с небольшим культурным капиталом (Roopnarine 2003), в то время как представители диаспоры в США - это в основном высококвалифицированные специалисты, такие как инженеры и врачи (Rajadesingan 2019). Таким образом, понимание факторов, влияющих на межкастовые браки в США, позволяет увидеть, как традиционные кастовые границы укрепляются в относительно привилегированном сообществе диаспоры в более широком западном контексте.

Традиционно в Индии брачного партнера для своих детей выбирают родителиэто брак по сговору. В настоящее время в индийском обществе практикуются различные варианты выбора брачного партнера. В одних семьях строго придерживаются традиции, в других - родители, подверженные современному веянию, считаются с мнением молодых и позволяют им самим выбирать себе пару. Результаты исследования, проведенного в рамках данного проекта, демонстрируют взгляды представителей индийской диаспоры, проживающих в Танзании, на этот счет. Наблюдается высокая значимость мнения родителей в выборе брачного партнера на современном этапе, однако большинство мужчин выразило желание самостоятельно принимать решения относительно будущей супруги. Такая же ситуация складывается и в Индии. Основываясь на данных официальной статистики в Индии, авторы исследуют тенденции в выборе супругов, продолжительность времени, в течение которого супруги знали друг друга до вступления в брак, межкастовые браки и родственные браки (Allendorf, Pandian 2016). В период с 1970 по 2012 год женщины все активнее выбирали себе мужей, число первых встреч супругов в день свадьбы уменьшалось, число межкастовых браков выросло, а число кровных браков падало. Однако многие из этих изменений были скромными по своим масштабам, а значительное большинство недавних браков все еще демонстрируют признаки организованного брака. Кроме того, вместо того чтобы игнорировать мнение родителей, молодые женщины 
все чаще сотрудничают с родителями в выборе будущего супруга. В отличии от широко распространенного в Индии способа поиска будущего партнера через брачные объявления в газетах и на сайтах знакомств (Дронова, Бутовская 2011), индийцы в Танзании редко к нему обращаются (Дронова 2014).

Респонденты в Танзании часто обращали внимание на то, что хотели бы супругу из Индии. В качестве объяснения приводили вполне конкретные примеры различий между невестами. Индийцы утверждают, что женщины из Индии лучше знают свою культуру, помнят все традиции, правильно исполняют церемонии жизненно цикла и религиозного календаря в отличии от местных индианок. Нередко встречаются случаи, когда мужчины специально выбирают себе будущую супругу из Индии. Интересно, что в среде марокканской диаспоры в Бельгии несмотря на высокую и даже возрастающую значимость религиозного фактора, партнера предпочитают выбирать непосредственно из представителей диаспоры, а не из Марокко, приводя совершенно противоположные индийцам аргументы (Sabbe et al. 2019). Марокканцы, обосновавшиеся в Бельгии, не хотят преодолевать образовавшуюся культурную пропасть между ними и марокканцами из Марокко, в том числе и усилившуюся лингвистическую проблему с постепенной утратой родного берберского языка - представители диаспоры констатируют о сложностях самовыражения на родном языке. Молодое поколение марокканцев в Бельгии утверждает, что у них больше общего с бельгийцами, чем с марокканцами, проживающими в Марокко. Девушки уверены, что разное этническое происхождение будущих супругов не может быть препятствием для заключения брака, однако важным для них остается принадлежность к одному и тому же религиозному течению - ислам. Более старшее поколение не согласно с такой позицией и считает, что залогом успешного брака является происхождение партнеров из одной культурной среды. Государственные меры по урегулирования миграционных потоков в Бельгии в том числе нарушают традицию принудительных браков среди представителей марокканской диаспоры, но браки по сговору продолжают ими практиковаться. В целом все перечисленные факты приводят к снижению уровня брачной миграции в этой общине.

\section{Выводы}

Наши данные полностью согласуются с результатами недавно опубликованного исследования, подтверждающего универсальные гендерные различия в выборе брачного партнера по 45 культурам: мужчины в большей степени, чем женщины, предпочитают привлекательных молодых партнерш, демонстрирующих репродуктивные возможности, а женщины в большей степени, чем мужчины, предпочитают партнеров старше себя с хорошими финансовыми перспективами (Walter et al. 2020). В тоже время культурные компоненты, характерные для индийского общества, оказывают влияние на выбор брачного партнера. Кастовая принадлежность, роль родительского мнения относительно будущего брачного партнера остаются важными критериями. Вместо одностороннего движения в сторону западных брачных установок, как это предполагается теориями изменения семьи и встречается в других азиатских контекстах (например, Китай), в Индии наблюдается промежуточный вариант совмещения традиционных индийских и западных норм. 


\section{Научная литература}

Бутовская М.Л., Дронова Д.А., Миханджо Э. Современные тенденции в выборе брачных партнеров у студентов-африканцев и отношение к традиционным установкам на продолжение рода и многодетность // Межрасовые и межэтнические отношения в современной Танзании: Труды Российской комплексной экспедиции в Объединенной Республике Танзания (сезон 2005 г.) / Отв. ред. А.В. Каратаев, Е.Б. Деминцева. М.: ЛЕНАНД, 2008. С. 168-195.

Бутовская М.Л., Смирнов О.В. Выбор постоянного полового партнера в среде современного московского студенчества: эволюционный анализ // Этнографическое обозрение. 2003. № 1. С. 141-163.

Дронова Д.А. Индийцы Дар-эс-Салама // Этнографическое обозрение. 2014. № 5. С. 175-185.

Дронова Д.А. Соприкосновение двух культур: представители индийской диаспоры и танзанийцы африканского происхождения (г. Дар-эс-Салам, Танзания) // Общество и государство в зеркале социологических измерений (VIII Рязанские социологические чтения). Материалы Национальной научно-практической конференции с международным участием / Отв. ред. Р.Е. Маркин, А.В. Проноза. 2018. С. 312-318.

Дронова Д.А., Бутовская М.Л. Выбор брачного партнера в современном индийском обществе и половой отбор // Восток (Oriens). Афро-азиатские общества: история и современность. 2011. № 6. С. 46-66.

Севериева Т.Ф. Жизненный путь женщины на Востоке // Мужчина и женщина в современном мире: меняющиеся роли и образы / ред. И.М. Семашко, А.Н. Седловская. М., 1999. С. 313-319.

Седловская А.Н. Женщина в традиционном сантальском обществе (Индия) // Мужчина и женщина в современном мире: меняющиеся роли и образы / ред. И.М. Семашко, А.Н. Седловская. М., 1999. С. 320-328.

Adur S.M., Narayan A. Stories of dalit diaspora: migration, life narratives, and caste in the us // Biography. 2017. Vol. 40 (1). P. 244-264.

Allendorf K., Ghimire D.J. Determinants of marital quality in an arranged marriage society // Social Science Research. 2013. Vol. 42 (1). P. 59-70.

Brauner-Otto S.R., Axinn W.G., Ghimire D.J. Parents' Marital Quality and Children's Transition to Adulthood // Demography. 2020. Vol. 57. P. 195-220. https://doi.org/10.1007/s13524-019-00851-w.

Buss D. M. Evolutionary Psychology. The New Science Of The Mind. Allyn and Bacon. 1999.

Buss D.M. Sex differences in human mate preferences: Evolutionary hypotheses tested in 37 cultures // Behavioral and Brain Sciences. 1989. Vol. 12. P. 1-49.

Buss D.M., Abbott M., Angleitner A., Asherian A., Biaggio A., Blanco-Villasenor A., ... Ekehammar $B$. International preferences in selecting mates: A study of 37 cultures // Journal of cross-cultural psychology. 1990. Vol. 21(1). P. 5-47.

Cherlin A.J., Kiernan K.E., Chase-Lansdale P.L. Parental divorce in childhood and demographic outcomes in young adulthood // Demography. 1995. Vol. 32. P.299-318.

Conroy-Beam D., Buss D.M. Why is age so important in human mating? Evolved age preferences and their influences on multiple mating behaviors // Evolutionary Behavioral Sciences. Vol. 13(2). 2019. P. 127-157. https://doi.org/10.1037/ebs0000127

Demir A., Fisiloglu H. Loneliness and marital adjustment of Turkish couples // The Journal of Psychology: Interdisciplinary and Applied. 1999. Vol. 133(2). P. 230-240. https://doi .org/10.1080/00223989909599736

Dunbar R.I.M., Waynforth D. Conditional mate choice strategies in humans: evidence from 'Lonely Hearts' advertisements // Behaviour. 1995. Vol. 132 (9-10). P. 755-779.

Flicker S.M., Sancier-Barbosa F., Afroz F., Saif S.N., Mohsin F. Marital quality in arranged and couple-initiated marriages: The role of perceived influence over partner selection // International Journal of Psychology. 2019. DOI: 10.1002/ijop.12622

Gupta U., Singh P. An exploratory study of love and liking and type of marriages // Indian Journal of Applied Psychology. 1982. Vol. 19. P. 92-97. 
Hoelter L.F., Axinn W.G., Ghimire D.J. Social change, premarital nonfamily experiences, and marital dynamics // Journal of Marriage and the Family. 2004. Vol. 66. P. 1131-1151.

Hortaçsu N. Family-versus couple-initiated marriages in Turkey: Similarities and differences over the family life cycle // Asian Journal of Social Psychology. 2007. Vol. 10 (2). P. 103-116. https:// doi.org/10.1111/j.1467-839X.2007.00217.x.

Hortaçsu $N$. The first year of family- and couple-initiated marriages of a Turkish sample: A longitudinal investigation // International Journal of Psychology. 1999. Vol. 34. P. $29-41$.

Kenrick D.T., Neuberg S.L., Zierk K.L., Krones J.M. Evolution and social cognition: contrast effects as a function of sex, dominance, and physical attractiveness // Personality and Social Psychology Bulletin. 1994. Vol. 20. P. 210-217.

Lev-Wiesel R., Al-Krenawi A. Attitude towards marriage and marital quality: A comparison among Israeli Arabs differentiated by religion // Family Relations. 1999. Vol. 48(1). P. 51-56. https:// doi.org/10.2307/585682.

Maira S. Desis in the house: Indian American youth culture in NYC. Temple University Press, 2012.

Malinen K., Kinnunen U., Tolvanen A., Ronka A., Wierda-Boer H., Gerris J. Happy spouses, happy parents? Family relationships among Finnish and Dutch dual earners // Journal of Marriage and Family. 2010. Vol. 72. P. 293-306.

Mealey L. Sex Differences: Developmental and Evolutionary Strategies. San Diego: Academic Press. 2000.

Murry T.R., Pujar L. Gender Based Potential Mate Preferences Among Emerging Adults // IMPACT: International Journal of Research in Applied, Natural and Social Sciences. 2018. Vol. 6 (2). P. 27-32.

Myers J.E., Madathil J., Tingle L.R. Marriage satisfaction and wellness in India and the United States: A preliminary comparison of arranged marriages and marriages of choice // Journal of Counseling and Development. 2005. Vol. 83. P. 183-190.

O'Kelly C.G., Carney L.S. Women and men in society: Crosscultural perspectives on gender stratification. Wadsworth Publishing, 1986.

Pawlowski B., Koziel S. The impact of traits offered in personal advertisements on response rates // Evolution and Human Behavior. 2002. Vol. 23 (2). P. 139-149.

Pimentel E.F. Just how do I love Thee? Marital relations in urban China // Journal of Marriage and the Family. 2000. Vol. 62. P. 32-47.

Rajadesingan A., Mahalingam R., Jurgens D. Smart, Responsible, and Upper Caste Only: Measuring Caste Attitudes through Large-Scale Analysis of Matrimonial Profiles // Proceedings of the International AAAI Conference on Web and Social Media. 2019. Vol. 13 (01). P. 393-404.

Regan P.C., Lakhanpal S., Anguiano C. Relationship outcomes in Indian-American love-based and arranged marriages // Psychological Reports. 2012. Vol. 110. P. 915-924.

Roopnarine L. East Indian indentured emigration to the Caribbean: Beyond the push and pull model // Caribbean studies. 2003. P. 97-134.

Roopnarine L. Indo-caribbean social identity // Caribbean quarterly. 2006. Vol. 52 (1). P. 1-11.

Sabbe A., El Boujaddayni K., Temmerman M., Leye E. Marriage and Migration: Moroccan Women's Views on Partner Choice, Arranged and Forced Marriage in Belgium // Journal of International Migration and Integration. 2019. Vol. 20. P. 1097-1120. https://doi.org/10.1007/s12134018-00646-9.

Schwartz S.A. The relationship between love and marital quality in arranged and romantic Jewish couples. Dissertation Abstracts International: Section B: The sciences and engineering. 2007. No. 68(4-b), 2716.

Shachar R. His and her marital satisfaction: The double standard // Sex Roles. 1991. Vol. 25. P. 451-467.

Symons D. The evolution of human sexuality. Oxford: Oxford University Press, 1979.

Thornton A., Axinn W.G., Xie Y. Marriage and cohabitation. Chicago, IL: University of Chicago Press. 2007. 
Trivers R.L. Parental investment and sexual selection, p. 136-179. In B. Campbell [ed.], Sexual selection and the descent of man, 1871-1971. Aldine-Atherton, Chicago, 1972.

Williams G.C. Sex and Evolution. Princeton, NJ: Princeton University Press, 1975.

$X u$ X., Whyte K.J. Love matches and arranged marriages: A Chinese replication // Journal of Marriage and the Family. 1990. Vol. 52. P. 709-722.

Yelsma P., Athappilly K. Marriage satisfaction and communication practices: Comparisons among Indian and American couples // Journal of Comparative Family Studies. 1988. Vol. 19. P. 37-54.

\section{References}

Adur, S.M., and A. Narayan. 2017. Stories of dalit diaspora: migration, life narratives, and caste in the us. Biography 40 (1): 244-264.

Allendorf, K., and D.J. Ghimire. 2013. Determinants of marital quality in an arranged marriage society. Social Science Research 42 (1): 59-70.

Brauner-Otto, S.R., W.G. Axinn, and D.J. Ghimire. 2020. Parents' Marital Quality and Children's Transition to Adulthood. Demography 57: 195-220. https://doi.org/10.1007/s13524-01900851-w

Buss, D.M. 1989. Sex differences in human mate preferences: Evolutionary hypotheses tested in 37 cultures. Behavioral and Brain Sciences 12: 1-49.

Buss, D.M. 1999. Evolutionary Psychology. The New Science Of The Mind. Allyn and Bacon.

Buss, D.M., M. Abbott, A. Angleitner, A. Asherian, A. Biaggio, A. Blanco-Villasenor, ... and B. Ekehammar. 1990. International preferences in selecting mates: A study of 37 cultures. Journal of cross-cultural psychology 21 (1): 5-47.

Butovskaya, M.L., and O.V. Smirnov. 2003. Vybor postoiannogo polovogo partnera v srede sovremennogo moskovskogo studenchestva: evoliutsionnyi analiz [A Permanent Sexual Partner Choice among Modern Moscow Students: an Evolutionary Analysis]. Etnograficheskoe obozrenie 1: 141-163.

Butovskaya, M.L., D.A. Dronova, and E. Mikhandzho. 2008. Sovremennye tendentsii v vybore brachnykh partnerov u studentov-afrikantsev i otnoshenie $\mathrm{k}$ traditsionnym ustanovkam na prodolzhenie roda i mnogodetnost' [Current Trends in the Choice of Marriage Partners among African Students and Attitudes to Traditional Attitudes to Procreation and Multiple Children]. In Mezhrasovye i mezhetnicheskie otnosheniia v sovremennoi Tanzanii: Trudy Rossiiskoi kompleksnoi ekspeditsii v Ob"edinennoi Respublike Tanzaniia (sezon 2005 g.), edited by A.V. Karataev and E.B. Demintseva, 168-195. Moscow: LENAND.

Cherlin, A.J., K.E. Kiernan, and P.L. Chase-Lansdale. 1995. Parental divorce in childhood and demographic outcomes in young adulthood. Demography 32: 299-318.

Conroy-Beam, D., and D.M. Buss. 2019. Why is age so important in human mating? Evolved age preferences and their influences on multiple mating behaviors. Evolutionary Behavioral Sciences 13 (2): 127-157. https://doi.org/10.1037/ebs0000127

Demir, A., and H. Fisiloglu. 1999. Loneliness and marital adjustment of Turkish couples. The Journal of Psychology: Interdisciplinary and Applied 133 (2): 230-240. https://doi .org/10.1080/00223989909599736

Dronova, D.A. 2014. Indiitsy Dar-es-Salama [Indians of Dar es Salaam]. Etnograficheskoe obozrenie 5: 175-185.

Dronova, D.A. 2018. Soprikosnovenie dvukh kul'tur: predstaviteli indiiskoi diaspory i tanzaniitsy afrikanskogo proiskhozhdeniia (g. Dar-es-Salam, Tanzaniia) [Contact between Two Cultures: Representatives of the Indian Diaspora and Tanzanians of African Descent (Dar es Salaam, Tanzania)]. In Obshchestvo i gosudarstvo v zerkale sotsiologicheskikh izmerenii (VIII Riazanskie sotsiologicheskie chteniia). Materialy Natsional'noi nauchno-prakticheskoi konferentsii s mezhdunarodnym uchastiem, edited by R.E. Markin and A.V. Pronoza, 312-318. Moscow: OOO "Izdatel'stvo Ippolitova". 
Dronova, D.A., and M.L. Butovskaya. 2011. Vybor brachnogo partnera v sovremennom indiiskom obshchestve i polovoi otbor [A Marriage Partner Choice in Modern Indian Society and Sexual Selection]. Vostok (Oriens). Afro-aziatskie obshchestva: istoriia i sovremennost' 6: 46-66.

Dunbar, R.I.M., and D. Waynforth. 1995. Conditional mate choice strategies in humans: evidence from 'Lonely Hearts' advertisements. Behaviour 132 (9-10): 755-779.

Flicker, S.M., F. Sancier-Barbosa, F. Afroz, S.N. Saif, and F. Mohsin. 2019. Marital quality in arranged and couple-initiated marriages: The role of perceived influence over partner selection. International Journal of Psychology. DOI: 10.1002/ijop.12622

Gupta, U., and P. Singh. 1982. An exploratory study of love and liking and type of marriages. Indian Journal of Applied Psychology 19: 92-97.

Hoelter, L.F., W.G. Axinn, and D.J. Ghimire. 2004. Social change, premarital nonfamily experiences, and marital dynamics. Journal of Marriage and the Family 66: 1131-1151.

Hortaçsu, N. 1999. The first year of family- and couple-initiated marriages of a Turkish sample: A longitudinal investigation. International Journal of Psychology 34: 29-41.

Hortaçsu, N. 2007. Family-versus couple-initiated marriages in Turkey: Similarities and differences over the family life cycle. Asian Journal of Social Psychology 10 (2): 103-116. https://doi. $\operatorname{org} / 10.1111 / \mathrm{j} .1467-839 X .2007 .00217 . x$

Kenrick, D.T., S.L. Neuberg, K.L. Zierk, and J.M. Krones. 1994. Evolution and social cognition: contrast effects as a function of sex, dominance, and physical attractiveness. Personality and Social Psychology Bulletin 20: 210-217.

Lev-Wiesel, R., and A. Al-Krenawi. 1999. Attitude towards marriage and marital quality: A comparison among Israeli Arabs differentiated by religion. Family Relations 48 (1): 51-56. https:// doi.org/10.2307/585682

Maira, S. 2012. Desis in the house: Indian American youth culture in NYC. Temple University Press,

Malinen, K., U. Kinnunen, A. Tolvanen, A. Ronka, H. Wierda-Boer, and J. Gerris. 2010. Happy spouses, happy parents? Family relationships among Finnish and Dutch dual earners. Journal of Marriage and Family 72: 293-306.

Mealey, L. 2000. Sex Differences: Developmental and Evolutionary Strategies. San Diego: Academic Press.

Murry, T.R., and L. Pujar. 2018. Gender Based Potential Mate Preferences Among Emerging Adults. IMPACT: International Journal of Research in Applied, Natural and Social Sciences 6 (2): 27-32.

Myers, J.E., J. Madathil, and L.R. Tingle. 2005. Marriage satisfaction and wellness in India and the United States: A preliminary comparison of arranged marriages and marriages of choice. Journal of Counseling and Development 83: 183-190.

O'Kelly, C.G., and L.S. Carney. 1986. Women and men in society: Crosscultural perspectives on gender stratification. Wadsworth Publishing Company.

Pawlowski, B., and S. Koziel. 2002. The impact of traits offered in personal advertisements on response rates. Evolution and Human Behavior 23 (2): 139-149.

Pimentel, E.F. 2000. Just how do I love Thee?: Marital relations in urban China. Journal of Marriage and the Family 62: 32-47.

Rajadesingan, A., R. Mahalingam, and D. Jurgens. 2019. Smart, Responsible, and Upper Caste Only: Measuring Caste Attitudes through Large-Scale Analysis of Matrimonial Profiles. Proceedings of the International AAAI Conference on Web and Social Media 13 (01): 393-404.

Regan, P.C., S. Lakhanpal, and C. Anguiano. 2012. Relationship outcomes in Indian-American love-based and arranged marriages. Psychological Reports 110: 915-924.

Roopnarine, L. 2003. East Indian indentured emigration to the Caribbean: Beyond the push and pull model. Caribbean studies 31 (2): 97-134.

Roopnarine, L. 2006. Indo-caribbean social identity. Caribbean quarterly 52 (1): 1-11.

Sabbe, A., K. El Boujaddayni, M. Temmerman, and E. Leye. 2019. Marriage and Migration: 
Moroccan Women's Views on Partner Choice, Arranged and Forced Marriage in Belgium. Journal of International Migration and Integration 20: 1097-1120. https://doi.org/10.1007/ s12134-018-00646-9

Schwartz, S.A. 2007. The relationship between love and marital quality in arranged and romantic Jewish couples. Dissertation Abstracts International: Section B: The sciences and engineering. 68 (4-b), 2716.

Sedlovskaia, A.N. 1999. Zhenshchina v traditsionnom santal'skom obshchestve (Indiia) [Women in Traditional Santhali Society (India)]. In Muzhchina i zhenshchina v sovremennom mire: meniaiushchiesia roli i obrazy, edited by I.M. Semashko and A.N. Sedlovskaia, 320-328. Moscow.

Severtseva, T.F. 1999. Zhiznennyi put' zhenshchina na Vostoke [Life Path of a Woman in the East]. In Muzhchina i zhenshchina v sovremennom mire: meniaiushchiesia roli i obrazy, edited by I.M. Semashko and A.N. Sedlovskaia, 313-319. Moscow.

Shachar, R. 1991. His and her marital satisfaction: The double standard. Sex Roles 25: 451-467.

Symons, D. 1979. The evolution of human sexuality. Oxford: Oxford University Press.

Thornton, A., W.G. Axinn, and Y. Xie. 2007. Marriage and cohabitation. Chicago: University of Chicago Press.

Trivers, R.L. 1972. Parental investment and sexual selection. In Sexual selection and the descent of man, 1871-1971, edited by B. Campbell, 136-179. Aldine, Chicago.

Williams, G.C. 1975. Sex and Evolution. Princeton. NJ: Princeton University Press.

$\mathrm{Xu}, \mathrm{X}$., and K.J. Whyte. 1990. Love matches and arranged marriages: A Chinese replication. Journal of Marriage and the Family 52: 709-722.

Yelsma, P., and K. Athappilly. 1988. Marriage satisfaction and communication practices: Comparisons among Indian and American couples. Journal of Comparative Family Studies 19: 37-54.

Dronova, Daria A., Butovskaya, Marina L.

\section{Mating preferences of men and women among the Indian diaspora in Tanzania}

The article presents the results of a study conducted among the Indian diaspora in Tanzania. The data obtained confirm the existence of universal gender differences in the mating preferences and are consistent with the predictions of the theory of sexual strategies. Indian men tend to pay more attention to a woman's reproductive abilities, thus evaluating physical indicators of fertility, health and age, as well as the potential to be a caring mother. Women appreciate those male qualities that reflect his ability to provide for a family (and therefore joint children), such as intelligence, good education, social status, diligence, financial security, etc. At the same time, cultural components typical for Indian society influence the mating preferences. Caste and the role of parents' opinion regarding the future marriage partner remain important criteria. Instead of a one-way movement towards Western marriage practices, as suggested by family change theories and as can be seen in other Asian contexts (such as China), trends in Indian society point to a combination of traditional Indian and Western practices.

Keywords: mating preferences, Indian diaspora, arranged marriage, India, Tanzania 